\title{
EFFECTIVE METHODS FOR RECLAMATION OF AREA SOURCES OF DUST EMISSION
}

\author{
Aleksandr Danilov' ${ }^{1}$, Yuri Smirnov ${ }^{1}$, Denis Korelskiy ${ }^{1}$ \\ 1 Geoecology Department, Saint-Petersburg Mining University, 2, 21st Line, Saint-Petersburg, 199106, Russia, \\ e-mail: aleksandrsdanilov@gmail.com
}

Received: 2017.05.05

Accepted: 2017.08.01

Published: 2017.09.01

\begin{abstract}
This article presents the results of the Shared equipment Center's work in the field of developing new methods for reclamation of dumps and waste storage sites, including methods for restoring the bioproductivity of clay soils, increasing the fertility of lowfertility soils, or potentially fertile soils, while increasing the protection of reclaimed lands from wind erosion.
\end{abstract}

Keywords: reclamation, bioremediation, dust emissions, technogenic massif

\section{INTRODUCTION}

Open pit mining is a source of danger for both employees of mining companies, as well as for the environment, residents of nearby settlements. Activity of mining enterprises is characterized by a large number of emissions of harmful substances - gases and dust - into the atmosphere, but no less hazardous for the environment are rock dumps [Androchanov, 2012].

In accordance with the Russian legislation (Land Code), after the operation of the land plot, it is necessary «to perform the necessary works for reclamation of the land plot, as well as perform other duties established by the law and (or) the lease agreement of the land plot».

The process of reclamation consists of two stages: mining-technical - it is standard, and biological. It takes small costs to reclaim and its environmental efficiency that can allow the owners of industries to comply with the relevant law. Therefore, finding effective and inexpensive ways to restore disturbed lands and reduce wind erosion (and dust formation) for a particular enterprise will ensure the emergence of new agricultural land.

During extraction and processing of minerals, significant dust flows and large areas of disturbed lands are formed. According to approxi- mate calculations, the total area of Russia's lands damaged by mining operations as a result of coal mining is 190 thousand hectares, by the extraction of ferrous and non-ferrous ores - about 350 thousand hectares, by the development of building rocks - more than 290 thousand hectares.

Air pollution in the areas of intensive dusting (separation of rocks from the array, transportation, pouring and the formation of heaps) reaches more than $1000 \mathrm{mg} / \mathrm{m}^{3}$. The dust that is most dangerous to humans (less than 10 micron) may hover in air for several hours and to move long distances, causing silicosis not only in workers but also the residents of nearby populated areas [Korshunov et al., 2014].

According to the existing technology of processing minerals, 30 to $70 \%$ of the feedstock passes into tailing dumps. Under appropriate weather conditions these areas are subjected to wind erosion and become intense sources of dust, because they contain virtually no particles larger than 2 $\mathrm{mm}$ and indirect environmental disturbance manifested in several tens of kilometers from the center of the storage man-made structures.

The incidence of the population in the areas with unprotected dusting surfaces of dumps and tailings is 1.5 times higher than in the areas where they are absent. Also, significant dusting leads to vegetation depression. 


\section{METHODS AND MATERIALS}

In this regard, there is a need to develop effective and efficient methods to restore damaged soils by mining operations, improve their biological productivity, consolidation of dusty surfaces, reducing the impact of waste volumes of mining on human health.

Figure 1 shows typical methods of dust suppression of area sources, which are divided into non-bio-efficient and bio-efficient (methods with elements of biological reclamation). In the laboratories of the Mining University, new methods of dust suppression, including combined ones, are developed.

One of the most promising areas for the development of rational nature management is the use of sapropel for effective dust suppression [Kovshov, 2009]. Sapropel is a freshwater silt. It is a mixture of soil deposited in freshwater reservoirs with half-decomposed plant and animal remains. Sapropel contains organic substances (up to $15-30 \%$ or more), nitrogen, phosphorus, potassium, lime, trace elements, some vitamins, antibiotics, biostimulants. Sapropel is used as a fertilizer in its pure form, and in the form of composts with manure, faeces or slurry [Pashkevich et al., 2012].

Before introducing into soil, the silt is aerated so that the nitrous compounds, harmful to plants, turn into oxide compounds. Silt is prepared both in summer and in winter. When preparing composts, one ton of sapropel is taken with 0.2 tons of manure. They are particularly effective on acid podzolic and light sandy and sandy loamy soils. The dose of compost for vegetable crops and potatoes, depending on the nutrient content $-6-7$ kg per 1 sq. $\mathrm{m}$.

The main components necessary for plant nutrition, such as $\mathrm{SiO}_{2}, \mathrm{~K}_{2} \mathrm{O}, \mathrm{P}_{2} \mathrm{O}_{5}, \mathrm{CaO}$, etc., are contained in sapropel in both gross and mobile forms. When using sapropel as a fertilizer, the soil receives nitrogen and phosphorus 2 times more than what ordinary mineral fertilizers can produce.

The use of sapropel in conjunction with mineral fertilizers improves their physical properties - the effect disappears caking of fertilizers, as well as a longer holding them in the soil.

The main reason for the low fertility of soils of dumps, in particular sand, is the negligible content of silty fraction in them. Since nutritious elements are mainly concentrated in the clay fraction, that is, sandy soils, which are always characterized by a lower content of these elements than their analogues of medium and heavy texture.

Therefore, to provide crop plants with nutrients, sandy soils, to a greater extent than others, require the use of mineral and organic fertilizers. But because of the lack of content of clay fraction in technogenic massifs, the absorption capacity of these soils is low, while water permeability, on the contrary, is very high. Therefore, they cannot

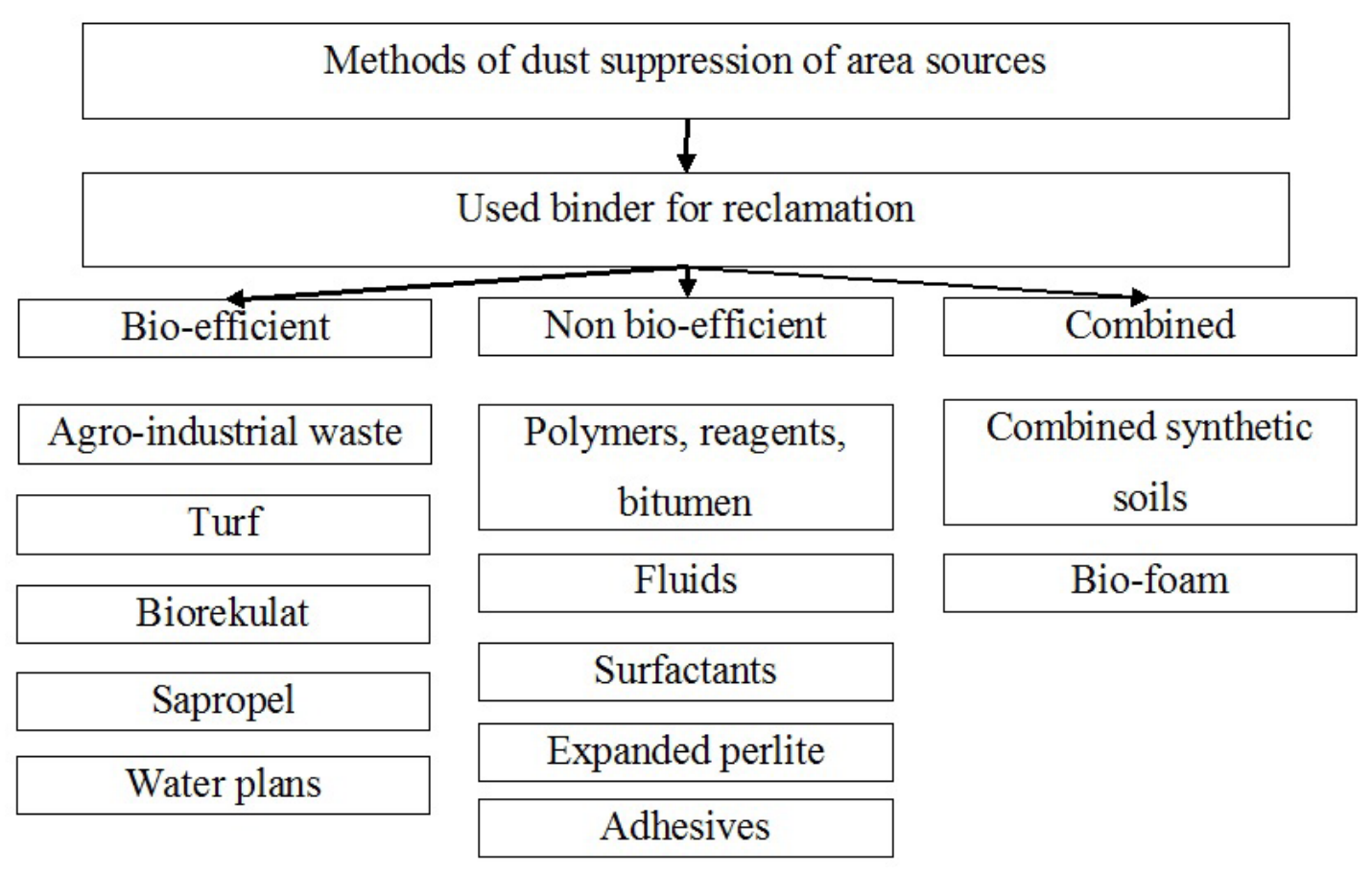

Fig. 1. Typical methods of dust suppression of area sources. 
retain a significant amount of water, and the water supply of plants is almost completely dependent on the frequency of precipitation.

In this regard, to increase the fertility of sandy soils, conventional measures widely applied on other soils, such as liming and applying mineral and organic fertilizers, are not enough. Without changing the mechanical composition of soils, that is, without increasing the silty fraction in them, all these measures are not effective enough and, in comparison with loamy soils, their payback is always considerably lower. Therefore, the use of sapropel is undoubtedly rational.

Obviously, sapropel is a very promising means of improving soil fertility. But for its application during the remediation of dumps, it is necessary to fulfill a number of conditions, the most important of which is the availability of sapropel for a particular mining enterprise.

Being by nature mud, sapropel concentrates on the bottom of the lakes, representing a mixture of mineral substances, inorganic components of biogenic origin, organic matter of dead aquatic plants and organisms living in the lake water, inhabiting its bottom and shore [Shtin, 2005]. It is established that in the placement of sapropelic deposits a certain regularity is observed, conditioned by climatic, geological, geomorphological, hydrogeological conditions and the nature of vegetation. It should be emphasized that the sapropelic deposits have not been studied evenly. The sapropelic deposits of the central regions of the European part of Russia and the Trans-Urals are relatively more thoroughly explored, while the sapropels of Eastern Siberia, the Far North and the Far East are almost completely unexplored. If we arbitrarily divide the territory of Russia into oblasts on sapropelenic accumulation, then we can conclude that the use of sapropels in the territory of the Leningrad Region during reclamation of mining dumps is absolutely justified, since the Kola-Karelian region is distinguished by an abundance of lakes of various origins. It is worth noting that in large lakes sapropel, often not, and for small lakes are characterized by different types of sapropel.

The technology for the use of sapropel is large, as the use of this substance contributes to the solution of a number of problems. For example, there are ways to restore the soil of dumps of cement production using sapropel.

The technical result is achieved by the fact that the method for restoring the land of cement dumps consists of adding sapropel, mixed with seeds of grasses in an amount of 25-30 $t /$ ha and smelling it to a depth of 4-6 cm as an organic fertilizer [Pashkevich et al., 2010].

Surface layer of dumps of cement production (screening) depth of 4-6 cm consists of marls, limestone, loam and sand. When sapropel is introduced into the screening in the amount of 25-30 $\mathrm{t} /$ ha to this depth, the content of sapropel and drop-out is $5-7 \%$ and $95-93 \%$ respectively.

Thus sapropel of organic (biogenic) type increases the content:

- soil moisture by $2-3 \%$;

- Humus from $2-2,5 \%$ to $3,5-4,5 \%$;

- $\mathrm{P}_{2} \mathrm{O}_{5}$ from $2.5-3.5 \%$ to $14.2-21.0 \mathrm{mg}$ per 100 $\mathrm{g}$ of soil;

- $\mathrm{K}_{2} \mathrm{O}$ from 8.0 to $8.4-10.5 \mathrm{mg}$ per $100 \mathrm{~g}$ of soil;

- $\mathrm{pH}$ from 5.2 to 7.0 for podzolic soils;

- hydrolytic acidity from $2.33-2.84$ to $0.3-0.53$ $\mathrm{mg} /$ eq per $100 \mathrm{~g}$ of soil.

More than $70 \%$ of the screening fractions exceed $0.5 \mathrm{~mm}$, and with natural sprinkling, sapropel penetrates between large cut-off fractions and void filling, which changes the mechanical properties of the created soil: increases the absorption capacity of the arable layer and reduces its water permeability. Sapropel also has the property of gluing together the finely divided mineral constituent of the soil, which allows to protect the formed soil from the effects of water and wind erosion.

Sapropel is an environmentally friendly product and completely biodegradable. Adding sapropel to the surface layer of cement plant dumps reduces the acidity of the soil, increases the content of humus and other nutrients $\left(\mathrm{K}_{2} \mathrm{O}, \mathrm{P}_{2} \mathrm{O}_{5}\right)$. The effectiveness of sapropel is maintained for 6 years.

Before inserting and plowing sapropel into the depth of arable layer of 4-6 cm, it is additionally ground and mixed with seeds of grasses or other agricultural plants. The introduction and plowing of sapropel in sowing in spring is considered optimal.

When using this method of land restoration, cement sapropel is used for fresh local reservoirs, which significantly reduces the costs of carrying out the biological stage of reclamation, and also increases the protective properties of the renewable surfaces from physical impact (water and wind erosion) and creates a fertile soil layer.

To increase the effectiveness of dust suppression, as well as to isolate toxic dumps, it is recom- 
mended to use bioactive foam based on sapropel, capable of forming chains (glued). To obtain a foam mixture, the gasification reaction is based on aluminum powder, which reacts with calcium hydroxide in an aqueous medium and releases hydrogen [Kovshov et al., 2014]:

$$
\begin{aligned}
& 2 \mathrm{Al}+3 \mathrm{Ca}(\mathrm{OH})_{2}+6 \mathrm{H}_{2} \mathrm{O}= \\
& =\mathrm{Ca}_{3}\left[\mathrm{Al}(\mathrm{OH})_{6}\right]_{2}+3 \mathrm{H}_{2} \uparrow
\end{aligned}
$$

The main components of bio-foam are sapropels, shredded wastes of flour-milling and grain processing industry (straw, leaves, reeds, bark) and additional carboxymethyl cellulose binder.

The use of waste mills and grain processing industries is undoubtedly rational. The number of secondary resources in the above industries reaches $90 \%$ of the processed raw materials. It is also possible to use crushed turf [Cole et al., 2012].

Experiments in laboratories showed high stability and bioactivity of the obtained bio-foam. It was established by experiments that after 3-4 hours the reaction of gas formation ceases and the resulting foam acquires the maximum multiplicity. The foam completely dries within 30-45 days. On the surface there is a dense crust that does not collapse during irrigation and subsequent drying, providing protection of the soil surface from dusting and destruction due to precipitation.

Three layers of formed bio-foam can be distinguished: the lower one consists of excess water and glue penetrating the surface layer of the dust dump, fixing it, the upper layer is the biofood layer itself, and between them the product of the gassing reaction - Torvaldson aluminate crystals, which further cement the dump surface .

Germination grass planted in the foam layer capacity to $3-5 \mathrm{~cm}$ in laboratory conditions ranges $70-100 \%$.

Application of sapropel allows to solve tasks on protection of the environment and human health. Biological and physical properties of sapropel allow using it in various technological schemes, the purpose of which is the restoration of soils disturbed by mining operations.

For long-term fixation of dusty surfaces and almost complete isolation of man-made massifs, it is necessary to carry out measures for application of bio-foam, which makes it possible to create a bio-productive coating that is resistant to wind loads.

Figure 2 shows the dependence of dust from the surfaces of technogenic massifs on the speed of air flow 2 hours after irrigation by the methods considered.

Based on the results of the research, the exponential dependence of dust extraction from the surfaces of technogenic massifs on the speed of air flow is established: for a surface without using methods of dust suppression, for a surface fixed with sapropel for a surface fixed with bio-foam. Thus, when using the developed methods, the dust emission decreases by more than 10 times.

Another method of fixing dust surfaces, developed at the Mining University, is to apply a mixture consisting of organic residues of natural origin and a high-molecular compound in a ratio of 125: 1 to dusting surfaces of stationary dust

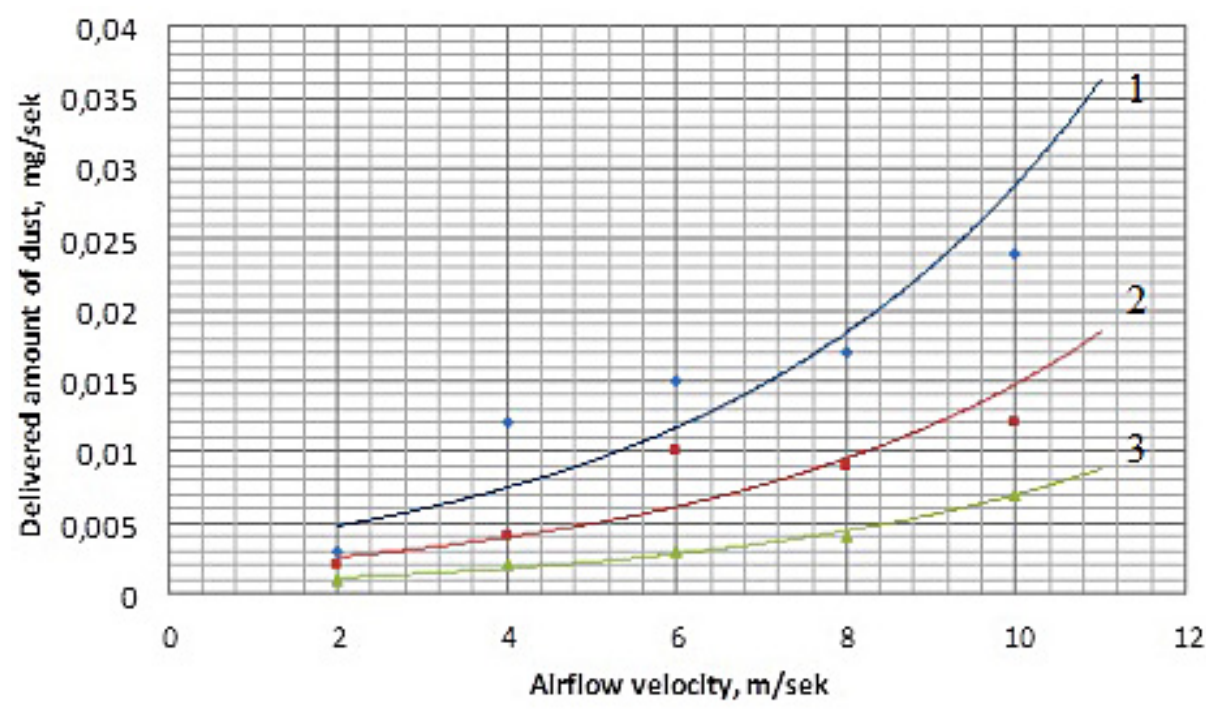

Fig. 2. Dependence of dust discharge from the surfaces of the man-made massifs air velocity. Flow after 2 hours after irrigation: 1 - without measures, 2 - strengthening sapropel, 3 - strengthening of biofeed. 
sources. As organic remains of natural origin, the biohumus obtained with the use of rain compost worms Eisenia Foetida is used. The technical result is also achieved by using sodium carboxymethyl cellulose as the high-molecular compound.

To prevent biodestructive processes when fixing the dusting surfaces, use of biohumus obtained with the use of rain compost worms Eisenia Foetida [Shuvalov et al., 2008].

Biohumus is a complex capillary-porous material, the intercellular space of which is filled with water with a low content of sucrose. In biohumus, obtained with the use of rain compost worms Eisenia Foetida, the solids content varies from 20 to $25 \%$, the $\mathrm{pH}$ has a slightly alkaline medium.

Biohumus is mixed with the sodium salt of carboxymethyl cellulose in a ratio of 125: 1 by volume to neutralize the medium to obtain an acidity equal to $\mathrm{pH} 7.1-7.4$, which is optimal for the formation of a further bioproductive medium based on a fixed dust surface. In this case, the adhesion ability of the sodium salt of carboxymethylcellulose will be preserved, which makes it possible to form a strong layer on a dusty surface that is weakly susceptible to destructive water and air erosion processes.

The method is carried out as follows:

1. Biohumus, obtained with the use of rain compost worms Eisenia Foetida, is used as organic residues of natural origin.

2. As a high-molecular compound having a high adhesiveness, the sodium salt of carboxymethylcellulose is used.

3. The application of the resulting mixture to the dusting surface and its fixation due to natural irrigation by rational agricultural machines for the application of organic fertilizers,

4. At the same time, it is necessary to add seed of grasses for subsequent removal of the surface.

5. Mixing of biohumus and sodium carboxymethyl cellulose in a ratio of 125: 1 is carried out by standard agricultural ring-spooled rollers, which loosened the top layer, bringing in the necessary components, and compacting the surface layer.
With natural sprinkling and gravity forces, the sodium salt of carboxymethylcellulose penetrates between the biohumus fractions and the dusting of the dust layer. The sodium salt of carboxymethylcellulose has an adhesive property to adhere fine mineral component of biohumus, which allows to protect the formed soil from the effects of water and wind erosion, but at the same time to form a bioproductive environment.

The resulting mixture was tested in a laboratory installation to create a wind load on pallets with different bioproductive layers of the same mass. The wind flow in the horizontal direction was $3 \mathrm{~m} / \mathrm{s}$ in the course of 1 minute. The results of the experiment are presented in Table 1.

Table 1 shows that the most durable and integral after blowing is a mixture with the composition 2. This suggests that exposure to wind erosion at a ratio of mixture of 2 components is minimal.

In comparison with the known solutions, the proposed method makes it possible to increase the effectiveness of fixing the dusting surface while simultaneously creating a bioproductive environment, which will facilitate the creation of secondary ecosystems on disturbed technogenic massifs.

Another problem that can be encountered during reclamation work is the preparation of soil mixture both at the site of reclamation work and the possibility of its transfer to different distances.

The technical result is achieved by the fact that the method for reconstructing disturbed lands in the open development of deposits including separate excavation, transfer and storage to individual soil heaps according to the invention, the soil groups are laid periodically to a heap height of $2.5 \mathrm{~m}$, when the sides of the heap 25-350 are flattened, The lower part of the group 15-20 cm thick is infertile overburden, the middle part of the group 10-12 cm thick is laid down by a natural ripper with a size of fractions no more than 10 $\mathrm{mm}$ and the upper part of the filling group It is treated with organic fertilizer, for example, sapropel with a moisture content of no more than $50 \%$, with a capacity of 5-7 cm.

Table 1. Results of the wind load experiment

\begin{tabular}{|c|c|c|c|c|c|}
\hline No. & $\begin{array}{c}\text { Biohumus, } \\
\%\end{array}$ & $\begin{array}{c}\text { Sodium salt of } \\
\text { carboxymethylcellulose, } \\
\%\end{array}$ & $\begin{array}{c}\text { Weight before blowing, } \\
\mathrm{g}\end{array}$ & $\begin{array}{c}\text { Weight after blowing, } \\
\mathrm{g}\end{array}$ & $\begin{array}{c}\text { Integrity of the formed } \\
\text { layer, } \%\end{array}$ \\
\hline 1 & 100 & 0 & 250 & 137 & 95 \\
\hline 2 & 99.2 & $\mathbf{0 . 8}$ & $\mathbf{2 5 0}$ & $\mathbf{2 4 5}$ & $\mathbf{9 5}$ \\
\hline 3 & 98.5 & 1.5 & 250 & 245 & 80 \\
\hline 4 & 97 & 3 & 250 & 244 & 50 \\
\hline 5 & 95 & 5 & 250 & 242 & 20 \\
\hline
\end{tabular}


The same technical result is achieved by using as a natural ripper a non-toxic waste of metallurgical production with a fractional composition of not more than $10 \mathrm{~mm}$, in as an organic fertilizer, turf is used.

The method consists in performing the following activities, shown in Fig. 3:

1. As infertile clay soil, a quarry is used to open a quarry of a construction pit with a thickness of $15-20 \mathrm{~cm}(1)$.

2. As a natural ripper, non-toxic cuttings of a quarry with a size of fractions of no more than $10 \mathrm{~mm}$ or non-toxic waste from metallurgical production using a fractional composition of not more than $10 \mathrm{~mm}$ are used and stacked with a power of 10-12 $\mathrm{cm} \mathrm{(2).}$

3. As an organic fertilizer, a sapropel (or peat), produced by means of a dredge or another method, is used with a capacity of 5-7 cm (3).

4. 1-3 points are repeated until reaching a collar height of $2.5 \mathrm{~m}$.

5. Under the forces of gravity and natural sprinkling in 9 months a bioproductive mixture is formed.

6. The obtained mixture is used for carrying out the biological stage of reclamation.

With natural sprinkling and forces of gravity, penetration of sapropel (peat) occurs between the cut-off fractions and the filling of voids (Figure 3 ), which changes the mechanical properties of the created soil: increases the absorptive capacity of the arable layer and reduces its water permeability. Sapropel also has the property of gluing together the finely divided mineral constituent of the soil, which allows to protect the formed soil from the effects of water and wind erosion.

It is possible to extract sapropel from the bottom of fresh water reservoirs or turf from near- by marshes using a dredger and transport to the site of reclamation.

The use of the composted soil obtained is rational after 9 months of milling as well as in the place of creating a soil dump, and on the entire surface of the areas necessary for reclamation.

\section{RESULTS}

Experiments in the laboratory have shown high stability and bio-activity. On the surface, there is a dense crust, which is not destroyed in the process of watering and subsequent draining, protecting the soil surface by sputtering and destruction due to precipitation.

Germination of grass planted in a foam layer capacity of up to $3-5 \mathrm{~cm}$ in the range of $70-95 \%$. District location reporting is the main mountainous terrain, which is the cause of the instability of the weather, Frequent and strong winds (up to $25-30 \mathrm{~m} / \mathrm{s}$ ) and an abundance of precipitation. The temperature regime during the year is unstable, which causes frequent thaws in the winter and in the summer frosts and snowfalls.

Wind speed and the stability of its direction is largely dependent on local conditions of the relief. Zonation observed climatic conditions: air temperature drop, an increase in precipitation, wind and snow cover duration with increasing altitude. A characteristic feature of the weather is its instability and rapid change caused by frequent changes in air masses moving cyclones and fronts. Monsoonal wind is weak. In general, for the year winds east-west direction (48\%) prevails over the meridian (11\%). The proposed variant of dust suppression satisfactorily tested in these climates and consequently can be applied in the same enterprises located in northern and central Europe.

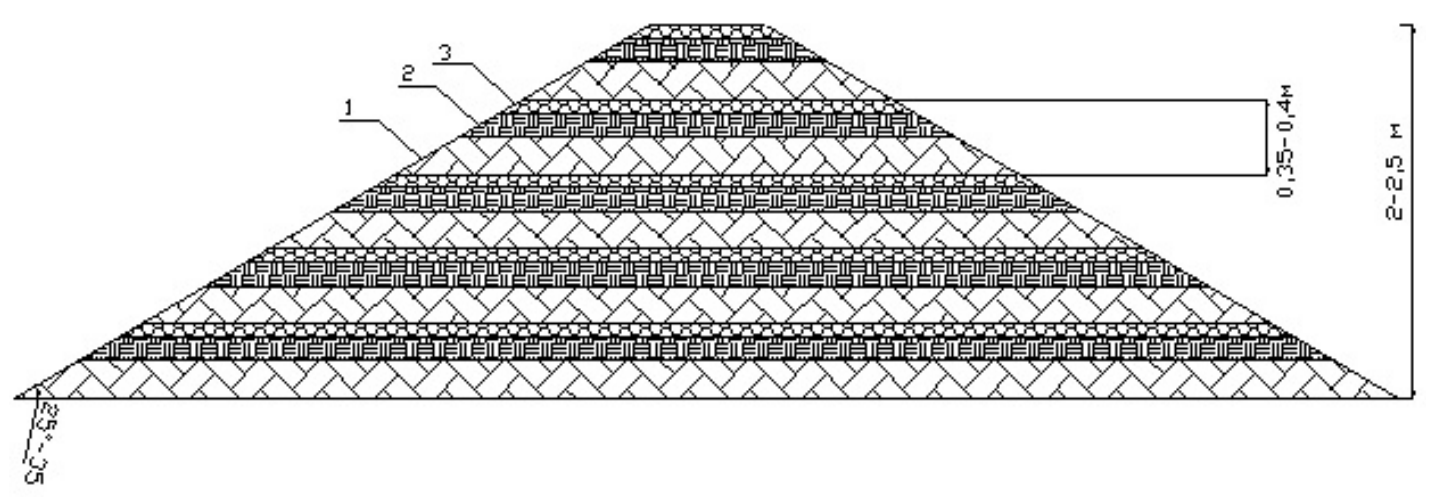

Fig. 3. The method of recovery of disturbed land at the open-cast mining of mineral deposits 
Using waste flour and grain processing industries undoubtedly rationally. The number of secondary resources in the above industries is as high as $90 \%$ of the feedstock. It is also possible to use milled peat. The implementation of this activity can significantly reduce the dusting of recently applied beach dump. The effectiveness of dust control, the implementation of the event and should be promptly responding employees, can be up to $96 \%$. Thus, is it possible to reduce the total emissions of dust into the air dump from 246.5 tons/year to 10.2 tons/year.

\section{CONCLUSIONS}

The scientific developments presented in this article have found application to scientific and educational work - participation in more than 30 research projects (since 2005) and at production, which is confirmed by the act of industrial implementation of the results of scientific activity at the Afanasyev quarry of cement raw materials of the branch of JSC «Lafarge cement» (Voskresensk), at the facilities of JSC "Apatite», joint work with the Institute of JV "PechorNIIproekt" (St. Petersburg).

According to the results of a decade of research at the Mining University have developed a number of inexpensive ways reclamation using local waste (non-hazardous) and potentially fertile soils (clay, sapropel, turf):

- new methods for reducing dust emissions into the atmosphere and restoring the biological productivity of disturbed areas in the areas of location of technogenic massifs by applying an organic bioactive binder based on sapropel or obtained biohumus allowing to create a bioproductive coating that is resistant to wind loads are developed.

- methods for shielding the bottom, walls and surfaces of man-made arrays have been proposed and developed to ensure safe warehousing of waste and improvement of adjacent territories and conservation of potential technogenic deposits using biopen of various compositions.
This article presents the results of the Shared Equipment Center's work in the field of developing new methods for reclamation of dumps and waste storage sites, including methods for restoring the bioproductivity of clay soils, increasing the fertility of low-fertility soils, or potentially fertile soils, while increasing the protection of reclaimed lands from wind erosion.

Strengthening the dusty surfaces of dumps, tailing dumps and other man-made formations will allow to reduce the level of atmosphere and soil pollution in the quarrying area, improve the ecological situation in such areas and will allow to successfully carry out the biological stage of reclamation.

\section{REFERENCES}

1. Androchanov V.A., 2012. Problems of reclamation northern territories. Advances in current natural sciences, 11(1), 28-31.

2. Cole, C.F., Fabrick, A.J., 2012. Surface Mine Pit Retention. Journal of the Air Pollution Control Association, 34 (6), 674-675.

3. Korshunov G.I. et al., 2014. Efficiency of application of surface-active substances for the pulverized coal struggle. Mining Informational-Analytical Bulletin, 3, 55-61.

4. Kovshov S.V., 2009. The problem of waste of organic origin and vermitechnology alternatively it solutions. Journal of Mining institute, 181. 217-219.

5. Kovshov S.V., Kovshov V.P., 2014. Biogenic fixation of dusting surfaces Life Science Journal, 11 (9), 401-404.

6. Pashkevich et al., 2010. RF patent No 2407891, Moscow, Federal Institute of Industrial Property.

7. Pashkevich et al., 2012. RF patent 2444628, Moscow, Federal Institute of Industrial Property.

8. Shtin S.M. 2005. Lake sapropel and their integrated development. Publisher Moscow Mining University.

9. Shuvalov U.V. et al., 2008 RF patent No 2338355 , Moscow, Federal Institute of Industrial Property. 